\title{
PENGETAHUAN REMAJA PUTRI TENTANG DAMPAK PERNIKAHAN DINI PADA KESEHATAN REPRODUKSI DI TASIKMALAYA
}

\author{
${ }^{1}$ Sofia Februanti \\ ${ }^{1}$ Dosen Jurusan Keperawatan Poltekkes Kemenkes Tasikmalaya
}

\begin{abstract}
Abstrak
Pernikahan dini merupakan suatu ikatan yang dilakukan oleh seseorang yang masih dalam usia muda atau pubertas. Pada tahun 2013 terjadi peningkatan rasio pernikahan muda pada daerah perkotaan, dibandingkan dengan daerah pedesaan. Tujuan penelitian ini Untuk mengetahui gambaran tingkat pengetahuan remaja putri tentang dampak pernikahan dini pada kesehatan reproduksi pada siswi di SMA Negeri 8 Kota Tasikmalaya. Desain penelitian yang digunakan adalah metode non eksperimen, yaitu metode deskriptif pengambilan data dilakukan pada 67 siswi dengan teknik proportional random sampling. Hasil penelitian tingkat pengetahuan, sebanyak $(53,7 \%)$ remaja putri memiliki pengetahuan tentang dampak pernikahan dini pada kesehatan reproduksi dengan kategori baik. Hasil dari penelitian ini diharapkan menjadi masukan bagi pihak sekolah dan keluarga agar lebih meningkatkan pengetahuan remaja putri dan bekerjasama dengan tenaga kesehatan untuk melakukan promosi kesehatan tentang dampak pernikahan dini pada kesehatan reproduksi wanita.
\end{abstract}

Kata kunci: dampak pernikahan dini, kesehatan reproduksi, pengetahuan, pernikahan dini

\begin{abstract}
Early marriage is a binding relationship formed by a person of early or puberty age. In 2013, there was an increase in the number of youngsisters marriage in the cities compared to the villages. The purpose of this study was to know a description of the teenager knowledge about the impact of marriage in the early reproductive health on female student in Senior High School 8 Tasikmalaya. The design of this study used experimental method, that is descriptive method a data done at random 67 female student with techniques proportional sampling. The result of research level of knowledge, as much as $(53,7 \%)$ tenangers had good knowledge about the impact of marriage in the early reproductive health. The result of this research is expected can be an input to the school and families to increase the knowledge of the teenager to do the health promotion about the impact of early marriage in woman reproduction health.
\end{abstract}

Keyword: knowledge, the wedding early, reproductive health, the impact of marriage early.

\section{PENDAHULUAN}

Masa remaja merupakan masa peralihan dari masa kanak-kanak yang tergantung menuju dewasa. Pada masa remaja individu menjadi mandiri serta terjadi perubahan fisik, mental, emosi, dan sosial. Remaja mengalami peralihan dari satu tahap kehidupan ke tahap berikutnya (Tukiran, 2010). Kematangan yang dimaksud adalah bukan hanya kematangan fisik saja, tetapi juga kematangan sosial dan psikologis. Saat ini kita sering dihadapkan dengan umur rata-rata remaja yang menikah dibawah usia antara 14-19 tahun (Widyastuti, 2009).

Pernikahan dini merupakan suatu ikatan yang dilakukan oleh seseorang yang masih dalam usia muda atau pubertas (Sarwono, 2007). Pada tahun 2013 terjadi peningkatan rasio pernikahan muda pada daerah perkotaan, dibandingkan dengan daerah pedesaan. Adapun jumlah rasio kenaikan pada daerah perkotaan pada 
tahun 2012 adalah 26 dari 1.000 pernikahan, rasio itu naik pada tahun 2013 menjadi 32 per 1.000 pernikahan. Sedangkan pada daerah pedesaan yang menurun dari 72 per 1000 pernikahan menjadi 67 per 1000 pernikahan pada tahun 2013 (Eko, 2014).

Sedangkan ditingkat Provinsi persentase perkawinan dini usia (15-19 th) tertinggi adalah Kalimantan Tengah (52,\%), Jawa Barat (50,2 persen), serta Kalimantan Selatan (48,4\%), Bangka Belitung (47,9\%) dan Sulawesi Tengah (46,3\%) (BKKBN, 2012). Untuk di Tasikmalaya menurut data di BKKBN (2012) tercatat 47 persen remaja di usia 19 tahun ke bawah telah menikah. Angka pernihakan usia dini ini ternyata paling dominan terdapat di Jawa Barat, dan salah satu wila-yah paling banyak berada di Kabupaten Tasikmalaya (Priangan, 2012).

Dampak dari pernikahan dini dilihat dari segi kesehatan, dapat berpengaruh pada tingginya angka kematian ibu yang melahirkan, kematian bayi serta berpengaruh pada rendahnya derajat kesehatan ibu dan anak. Sehingga melahirkan pada usia kurang dari 20 tahun mengandung resiko tinggi dan ibu hamil usia 20 tahun ke bawah sering mengalami prematuritas (lahir sebelum waktunya) besar kemungkinan cacat bawaan, fisik maupun mental, kebutaan dan ketulian. Sedangkan usia yang kecil resikonya dalam melahirkan adalah antara usia 20-35 tahun (Prawiroharjo, 2011).

Berdasarkan data dari KUA kecamatan Tamansari kota Tasikmalaya didapatkan data jumlah nikah selama tahun 2015 yaitu sebanyak 627. Pria yang menikah di usia 19-20 tahun sebanyak 22 orang, pria yang menikah di usia 21-24 tahun sebanyak 165 orang, sedangkan pria yang menikah diusia 25 tahun keatas sebanyak 320. Hal tersebut berbanding terbalik dengan wanita. Sepanjang 2015 wanita yang menikah diusia 16-20 tahun sebanyak 253 orang, wanita yang menikah diusia 21-24 tahun sebanyak 167, sedangkan wanita yang menikah diusia 25 tahun keatas sebanyak 71 orang. Dari data tersebut memperlihatkan bahwa masih banyak nya angka pernikahan dini pada mempelai wanita diusia 16-20 tahun. Dari hasil studi pendahuluan sekolah yang ada di kecamatan Tamansari yaitu di SMAN 8 Tasikmalaya dengan wawancara kepada pihak sekolah, menyatakan memang belum ada promosi kesehatan tentang pendidikan seks ataupun tentang dampak pernikahan dini.

Sementara itu hasil wawancara dengan 8 siswi di dapatkan 3 diantaranya mengatakan bahwa mengetahui tentang dampak yang akan terjadi bila menikah di usia dini salah satunya akan berdampak pada psikologisnya dan kesehatan rahim wanitanya. Sedangkan 5 diantaranya mengatakan tidak tahu dampak yang akan terjadi apabila menikah di usia dini karena belum ada mengenai informasi tersebut. Berdasarkan fenomena diatas, maka peneliti tertarik untuk meneliti permasalahan tersebut dengan judul "Gambaran tingkat pengetahuan remaja putri tentang dampak pernikahan dini pada kesehatan reproduksi di SMA Negeri 8 kota Tasikmalaya". Tujuan penelitian ini adalah untuk mengetahui gambaran tingkat pengetahuan remaja putri tentang dampak pernikahan dini pada kesehatan reproduksi pada siswi di SMA Negeri 8 Tasikmalaya. Manfaat penelitian ini adalah untuk mengetahui pengetahuan remaja putri tentang dampak pernikahan dini pada kesehatan reproduksi sehingga remaja putri dapat menghindari kejadian pernikahan dini.

\section{METODE PENELITIAN}

Desain penelitian menggunakan metode non eksperimen deskriptif, yaitu untuk menggambarkan secara objektif tingkat pengetahuan remaja putri tentang dampak pernikahan dini pada kesehatan reproduksi di SMA Negeri 8 Tasikmalaya. Populasi penelitian adalah seluruh remaja putri di SMA Negeri 8 Tasikmalaya kelas XI yang berjumlah 207 orang. Teknik pengambilan sampel menggunakan teknik proportional random sampling. Jumlah sampel yang dibutuhkan dari kelas XI siswi 
SMA Negeri 8 Kota Tasikmalaya yaitu berjumlah 67 siswi. Adapun kriteria inklusi dan kriteria eksklusi dalam penelitian ini adalah sebagai berikut: Siswi SMA Negeri 8 Tasikmalaya yang sedang aktif bersekolah saat penelitian berlangsung, bersedia menjadi responden. Etika penelitian dengan memberikan informed consent sebelum calon responden menyetujui untuk dilakukan pengambilan data.

Instrumen penelitian yang digunakan adalah kuesioner, berjumlah 22 soal, meliputi tentang pernikahan dini, kesehatan reproduksi, dampak pernikahan dini. Uji Validitas dan reliabilitas kuesioner penelitian dilaksanakan di SMA Negeri 10 Tasikmalaya pada 35 responden. Analisa data dengan menggunakan analisis univariate, untuk menganalisa dilakukan dengan teknik presentase.

\section{HASIL PENELITIAN}

Tabel 1. Distribusi frekuensi pengetahuan remaja putri tentang pernikahan dini

\begin{tabular}{cccc}
\hline No & Pengetahuan & $\mathbf{F}$ & $\%$ \\
\hline 1 & Baik & 40 & 59,7 \\
\hline 2 & Cukup & 23 & 34,3 \\
\hline 3 & Kurang & 4 & 6,0 \\
\hline & Jumlah & 67 & 100
\end{tabular}

Berdasarkan tabel 1, pengetahuan remaja putri tentang pernikahan dini di SMA Negeri 8 Tasikmlaya didapatkan data presentase tertinggi sebagian dari responden yaitu memiliki pengetahuan kategori baik sebanyak 40 orang $(59,7 \%)$.

Tabel 2. Distribusi frekuensi pengetahuan remaja putri tentang kesehatan reproduksi

\begin{tabular}{clcc}
\hline No & Pengetahuan & F & $\%$ \\
\hline 1 & Baik & 56 & 83,6 \\
\hline 2 & Cukup & 9 & 13,4 \\
\hline 3 & Kurang & 2 & 3,0 \\
\hline & Jumlah & 67 & 100 \\
\hline
\end{tabular}

Berdasarkan table 2, pengetahuan remaja putri tentang kesehatan reproduksi di SMA Negeri 8 Tasikmalaya didapatkan data presentase tertinggi sebagian dari responden yaitu memiliki pengetahuan kategori baik sebanyak 56 orang (83,6 \%).

Tabel 3. Distribusi frekuensi pengetahuan remaja putri tentang dampak pernikahan dini

\begin{tabular}{clcc}
\hline No & Pengetahuan & $\mathrm{F}$ & $\%$ \\
\hline 1 & Baik & 24 & 35,8 \\
\hline 2 & Cukup & 14 & 20,9 \\
\hline 3 & Kurang & 29 & 43,3 \\
\hline & Jumlah & 67 & 100 \\
\hline
\end{tabular}

Berdasarkan tabel 3, pengetahuan remaja putri tentang dampak pernikahan dini di SMA Negeri 8 Tasikmlaya didapatkan data presentase tertinggi sebagian dari responden yaitu memiliki pengetahuan kategori kurang sebanyak 29 orang $(43,3$ $\%)$.

Tabel 4. Distribusi frekuensi pengetahuan remaja putri tentang dampak pernikahan dini

\begin{tabular}{clcc}
\hline No & Pengetahuan & F & $\%$ \\
\hline 1 & Baik & 36 & 53.7 \\
\hline 2 & Cukup & 29 & 43.3 \\
\hline 3 & Kurang & 2 & 3.0 \\
\hline & Jumlah & 67 & 100 \\
\hline
\end{tabular}

Berdasarkan tabel 4, pengetahuan remaja putri tentang dampak pernikahan dini pada kesehatan reproduksi di SMA Negeri 8 Tasikmlaya didapatkan data presentase tertinggi sebagian dari responden yaitu memiliki pengetahuan dengan kategori baik sebanyak 36 orang $(53,7 \%)$.

\section{PEMBAHASAN}

Hasil penelitian tingkat pengetahuan remaja putri memiliki pengetahuan baik tentang pernikahan dini, Hasil penelitian ini menunjukan hasil yang berbeda dengan penelitian yang diteliti oleh Ermayanti tahun 2012 tentang resiko perkawinan dini dalam 
kehamilan. Hasil penelitian didapatkan sebagian besar responden memiliki pengetahuan kurang sebanyak 16 orang (53\%) (Ermayanti, 2012). Responden yang diteliti adalah remaja putri yang tinggal disuatu lingkungan masyarakat, sedangkan responden yang diteliti oleh peneliti adalah remaja putri yang sedang menempuh pendidikan Sekolah Menengah Atas (SMA) (Ermayanti, 2012).

Hal ini sejalan dengan pendapat Notoatmodjo (2005) bahwa Pendidikan merupakan proses belajar yang pernah ditempuh secara formal didalam lembaga pendidikan, karena semakin tinggi tingkat pendidikan, maka semakin tinggi pula tingkat pengetahuan dan kesadaran pada orang tersebut dalam menerima informasi. Sehingga masih ada sebagian remaja putri yang belum memahami apa itu pernikahan dini. Karena ketidaktahuan dan ketidakpahaman itu, maka remaja putri beresiko menikah dini. Karena kurang informasi yang mereka dapatkan.

Maka dari itu peneliti menganalisa aspek kognitif sebagian besar responden yang diteliti tentang pernikahan dini sudah baik, sehingga diharapkan remaja putri dapat memiliki sikap yang baik, dengan mampu merencanakan dan mengambil keputusan dengan tepat dimasa depan. Sehingga pernikahan diusia dini tidak terjadi.

Hasil penelitian Tingkat pengetahuan remaja putri memiliki pengetahuan baik tentang kesehatan reproduksi. Hasil penelitian ini menunjukan hasil yang sejalan dengan penelitian yang diteliti oleh Suryana tahun 2015 Tentang pendidikan seks pada siswa siswi dengan hasil sebagian besar tingkat pengetahuan remaja memiliki pengetahuan dengan kategori baik sebanyak 48 orang $(62,3 \%)$ (Suryana, 2015).

Menurut Effendi \& Makhfudli (2009) kesehatan reproduksi remaja adalah suatu kondisi sehat yang menyangkut sistem, fungsi, dan proses reproduksi yang dimiliki oleh remaja. Kesehatan reproduksi dikalangan remaja kini sudah tidak asing lagi. Mereka mendapat pengetahuan tentang kesehatan reproduksi ini dipengaruhi oleh berbagai sumber informasi. Menurut Pinem (2009) faktorfaktor yang dapat berpengaruh buruk terhadap kesehatan reproduksi remaja diantaranya masalah perkawinan dan kehamilan dini. Informasi seperti itu sebagian responden dapatkan melalui internet, bahkan di sekolah pun mereka terpapar informasi mengenai kesehatan reproduksi di pelajaran biologi meskipun tidak semua siswi mendapatkan informasi karena beda jurusan, karena terpaparnya informasi disekolah, serta dapat mengakses sendiri informasi sehingga responden memiliki pengetahuan yang baik. Maka dari itu peneliti menganalisa aspek kognitif sebagian besar responden yang diteliti sudah baik, Dengan pengetahuan yang baik akan berdampak kepada sikap remaja putri dan diharapkan sikap tersebut dapat ditunjukan dengan cara dirinya bertanggung jawab mengenai kesehatan reproduksinya serta dapat menghindari faktor-faktor yang dapat mempengaruhi kesehatan reproduksi diantaranya perkawinan dan kehamilan dini.

Hasil penelitian tingkat pengetahuan remaja putri memiliki pengetahuan kurang tentang dampak pernikahan dini. Hasil penelitian ini berbeda dengan yang diteliti oleh Fibriana tahun 2012 tentang hubungan antara usia dengan tingkat pengetahuan remaja tentang dampak pernikahan usia dini di MA Nurul islam Silo kabupaten Jember dengan hasil penelitian didapatkan Pada usia 16-19 tahun sebagian besar dari responden (52,94\%) yang mempunyai tingkat pengetahuan baik tentang dampak pernikahan usia dini yaitu sebanyak 18 orang (Fibriana, 2012). Perbedaan hasil tersebut dapat disebabkan oleh beberapa faktor yang mempengaruhi pengetahuan salah satunya sumber informasi, karena sumber informasi merupakan segala sesuatu yang menjadi perantara dalam penyampaian informasi, merangsang pikiran dan kemampuan. Media informasi untuk komunikasi massa terdiri dari media cetak yaitu surat kabar, majalah dan buku, dan media elektronik seperti radio, tv dan internet (Notoatmodjo, 2005). Ada kaitannya juga dengan informasi yang didapatkan responden, Sebagian responden masih kurang dalam menerima informasi tentang pernikahan dini yang tidak dapat diperoleh dari lingkungan masyarakat dan orang tuanya.

Dengan ketidaktahuan itu mereka kurang memahami tentang dampak pernikahan dini yang akan terjadi. Padahal dampak yang akan terjadi pada beberapa Pernikahan dini diantaranya dampak terhadap suami istri, dampak terhadap keluarga masing-masing, dampak terhadap 
kesehatan, dampak terhadap psikologis, dan dampak terhadap sosial.

Melihat berbagai macam dampak yang akan terjadi. Maka dari itu peneliti berpendapat rendahnya pengetahuan tersebut menjadikan bahwa pentingnya diberikan informasi mengenai dampak pernikahan dini pada siswi. Pengetahuan dari sekolah, lingkungan masyarakat serta orang tua sangat berperan bagi responden untuk memperoleh informasi yang akurat tentang dampak pernikahan dini. Peneliti menganalisa aspek kogntif responden yang diteliti masih kurang, sehingga remaja putri masih perlu informasi yang banyak untuk meningkatkan pengetahuannya tentang dampak pernikahan dini melalui sekolah, orang tua, dan lingkungan sekitar.

Hasil penelitian remaja putri memiliki pengetahuan baik tentang dampak pernikahan dini pada kesehatan reproduksi. Hasil penelitian ini menunjukan hasil yang berbeda dengan yang telah diteliti oleh Darmayanti tahun 2012 tentang dampak pernikahan dini pada kesehatan reproduksi. Didapatkan hasil sebagian besar tingkat pengetahuan remaja putri memiliki pengetahuan cukup sebanyak 35 orang $(58,33 \%)$ (Darmayanti, 2012). Perbedaan tersebut dapat disebabkan oleh jenis kurikulum yang bebeda, karena tujuan pendidikan di SMA dan SMK juga berbeda.

Masih adanya sebagian sisiwi yang kurang mengetahui dan memahami tentang dampak pernikahan dini pada kesehatan reproduksi, padahal banyak sekali dampak yang akan terjadi pada kesehatan reproduksi bila melakukan pernikahan dini mulai dari ibu hamil akan beresiko anemia, keracunan kehamilan, keguguran (Panga, 2013 dalam Ernawati \& Verawati, 2014). Pada saat melahirkan ibu juga beresiko perdarahan dan persalinan yang lama dan sulit (Lina, 2012 dalam (Ernawati \& Verawati, 2014). Dan pada masa nifas ibu beresiko infeksi dan perdarahan post partum (Ernawati \& Verawati, 2014).

Melihat berbagai macam dampak yang akan terjadi, maka tingkat pengetahuan remaja putri tentang dampak pernikahan dini sangat penting diberikan untuk meningkatkan pengetahuan mereka melalui orang tua, sekolah dan lingkungan masyarakat. Peneliti menganalisa aspek kognitif sebagian besar responden yang diteliti tentang dampak pernikahan dini pada kesehatan reproduksi sudah baik, diharapkan orang tua tetap terus mengingatkan informasi yang sudah diterima anaknya tentang bahaya pernikahan dini pada kesehatan reproduksinya. Diharapkan juga remaja putri dapat memiliki sikap yang bertanggung jawab, remaja putri mampu merencanakan masa depan yang baik dan mampu membuat suatu keputusan dengan bijak agar pernikahan dini tidak terjadi dan kesehatan reproduksi mereka tetap sehat dan terhindar dari faktor-faktor yang berpengaruh buruk terhadap kesehatan reproduksinya yaitu pernikahan dini.

\section{KESIMPULAN}

Hasil penelitian dapat disimpulkan bahwa sebagian besar remaja putri memiliki pengetahuan baik tentang pernikahan dini dan kesehatan reproduksi. Namun masih kurang baik dalam mengetahui dampak pernikahan dini.

\section{SARAN}

Diharapkan penelitian ini menjadi masukan bagi pihak sekolah agar lebih meningkatkan pengetahuan siswinya dan juga pihak sekolah terutama untuk guru BK (bimbingan konseling) mengupayakan setiap siswinya mengikuti bimbingan konseling, dimana didalam konseling tersebut siswi selain diberitahukan informasi mengenai dampak pernikahan dini pada kesehatan reproduksi. Siswi juga diharapkan dapat berkonseling dengan guru BK untuk merencanakan dan menentukan masa depannya lebih baik sehingga tidak terjadi lagi pernikahan usia dini. Diharapkan peneliti yang akan datang untuk meneliti lebih jauh tentang tentang dampak pernikahan dini pada kesehatan reproduksi, agar lebih mengembangkan variabel penelitian serta kuesioner dengan metode penelitian yang lainnya, dan pada waktu dan tempat yang berbeda sehingga didapatkan hasil penelitian yang lebih baik.

\section{DAFTAR PUSTAKA}

BKKBN. (2012). Kajian pernikahan dini pada beberapa provinsi di Indonesia. Jakarta.

Darmayanti, I. (2012). Hubungan antara usia dengan tingkat pengetahuan remaja tentang dampak pernikahan usia dini di 
ma nurul islam silo kabupaten jember. Retrieved June 19, 2016, from http://digilib.stikeskusumahusada.ac.id/ files/disk1/1/01-gdl-iradamayan 33-1iradama-i.pdf

Effendi, \& Makhfudli. (2009). Keperawatan Komunitas. Jakarta: Salemba Medika.

Eko, S. (2014). Pernikahan Dini Kembali jadi Tren Remaja Perkotaan. Retrieved February 22, 2016, from http://nasional.kompas.com/read/2014/ 01/27/0559177/Pernikahan.Dini.Jadi.Tr en.di.Perkotaan.

Ermayanti. (2012). Gambaran pengetahuan remaja putri tentang resiko Perkawinan dini dalam kehamilan di kelurahan Tanjung gusta lingkungan kecamatan Medan Helvetia Tahun 2012. Retrieved from http://balitbang.pemkomedan.go.id/tiny mcpuk/gambar/file/Erma Yanthi.pdf

Ernawati, \& Verawati. (2014). Kesehatan ibu dan bayi pada pernikahan dini. Retrieved February 21, 2016, from http://lib.umpo.ac.id/files/54207-bahanluaran-penelitian-BARU.pdf

Fibriana, F. (2012). Hubungan antara usia dengan tingkat pengetahuan remaja tentang dampak pernikahan usia dini di ma nurul islam silo kabupaten jember. Retrieved June 19, 2016, from http://www.academia.edu/9142991/hub ungan_antara_usia_dengan_tingkat _pengetahuan_remaja_tentang_damp ak_pernikahan_usia_dini

Notoatmodjo, S. (2005). Promosi kesehatan: Teori dan Aplikasi. Jakarta: Rineka Cipta.

Pinem, S. (2009). Kesehatan reproduksi dan Kontrasepsi. Jakarta: Trans Info Media.

Prawiroharjo. (2011). IImu Kebidanan. Jakarta: Yayasan Bina Pustaka Sarwono Prawiroharjo.

Priangan, S. Kabar. (2012). Angka Pernikahan Dini di Tasikmalaya Masih Tinggi. Retrieved February 21, 2016, from http://www.kabarpriangan.com/news/detail/6763

Sarwono, S. (2007). Psikologis Remaja. Jakarta: PT Rajagrafindo Persada.

Suryana, Y. (2015). Gambaran tingkat pengetahuan remaja tentang pendidikan seks pada siswa-siswi kls VIII SMP Negeri 17 kota Tasikmalaya. Poltekkes Kemenkes Tasikmalaya.

Tukiran, D. (2010). Keluarga Berencana dan Kesehatan Reproduksi. Yogyakarta: Pustaka Belajar.

Widyastuti, D. (2009). Kesehatan Reproduksi. Yogyakarta: Fitramaya. 